\title{
Impacts of air pollution and climate on materials in Athens, Greece
}

\author{
John Christodoulakis ${ }^{1}$, Chris G. Tzanis ${ }^{1}$, Costas A. Varotsos ${ }^{1}$, Martin Ferm ${ }^{2}$, and Johan Tidblad ${ }^{3}$ \\ ${ }^{1}$ Climate Research Group, Division of Environmental Physics and Meteorology, Department of Physics, National and \\ Kapodistrian University of Athens, University Campus Bldg. Phys. V, Athens 15784, Greece \\ ${ }^{2}$ IVL Swedish Environmental Research Institute Ltd., P.O. Box 53021, 40014 Gothenburg, Sweden \\ ${ }^{3}$ Corrosion and Metals Research Institute, Drottning Kristinas väg 48, 11428 Stockholm, Sweden
}

Correspondence to: Costas A. Varotsos (covar@phys.uoa.gr)

Received: 6 March 2016 - Published in Atmos. Chem. Phys. Discuss.: 8 June 2016

Revised: 5 October 2016 - Accepted: 6 December 2016 - Published: 10 January 2017

\begin{abstract}
For more than 10 years now the National and Kapodistrian University of Athens, Greece, has contributed to the UNECE (United Nations Economic Commission for Europe) ICP Materials (International Co-operative Programme on Effects on Materials including Historic and Cultural Monuments) programme for monitoring the corrosion/soiling levels of different kinds of materials due to environmental air-quality parameters. In this paper we present the results obtained from the analysis of observational data that were collected in Athens during the period 2003-2012. According to these results, the corrosion/soiling of the particular exposed materials tends to decrease over the years, except for the case of copper. Based on this long experimental database that is applicable to the multi-pollutant situation in the Athens basin, we present dose-response functions (DRFs) considering that "dose" stands for the air pollutant concentration, "response" for the material mass loss (normally per annum) and "function", the relationship derived by the best statistical fit to the data.
\end{abstract}

\section{Introduction}

Climatic parameters and air pollutants are of major significance in the deterioration of many materials used in buildings and cultural monuments (Ferm et al., 2005, 2006; Varotsos et al., 2009; Tzanis et al., 2009a, 2011; Tidblad et al., 2012). These pollutants are mainly emitted by industrial and agricultural activities as well as by the transport sector and, beyond their effects on human health and ecosystems, they contribute to the deterioration of cultural monuments both on the local scale and over long distances (Köhler et al., 2001; Ondov et al., 2006; Ebel et al., 2007; Tzanis et al., 2009b; Jacovides et al., 1994; Varotsos et al., 1994, 2012, 2014; Chattopadhyay et al., 2012; Krapivin and Shutko, 2012; Merlaud et al., 2012; Cracknell and Varotsos, 1994, 1995, 2007; Xue et al., 2014; Monks et al., 2015; Efstathiou and Varotsos, 2010, 2012, 2013). The world's cultural heritage is very diverse and costly to maintain. Repairing costs for deterioration of various materials due to air pollution, together with climatic parameters, are huge (Doytchinov et al., 2011), while the damage to cultural objects seriously endangers the cultural heritage.

Effective policy making requires an adequate scientific basis to assess the effects of pollution and climate change on materials. In this context, the United Nations Economic Commission for Europe (UNECE) adopted the Convention on Long-range Transboundary Air Pollution (CLRTAP) to address the problems of air pollution. In the framework of the UNECE/CLRTAP, the International Co-operative Programme on Effects on Materials including Historic and Cultural Monuments (ICP Materials) was launched in order to provide, among other objectives, a scientific basis for the study of important material degradation due to atmospheric pollution and climate parameters. Athens, Greece, which has significant cultural heritage monuments (UNESCO Cultural Heritage site: Acropolis, Parthenon), has been involved in ICP Materials since 2002 as a targeted field exposure test site, also participating in the EU project MULTI-ASSESS (Model for multi-pollutant impact and assessment of threshold levels for cultural heritage: http://www.corr-institute.se/ multi-assess/web/page.aspx).

An important contribution to this effort is the development of dose-response functions (DRFs) for particular ma- 
terials. DRFs are relationships between the corrosion or soiling rates and the levels or loads of pollutants in combination with climatic parameters. The corrosion is mainly caused by chemical reactions on the material surface involving air pollutants (e.g., $\mathrm{SO}_{2}, \mathrm{NO}_{x}$ and $\mathrm{O}_{3}$ ), while soiling is principally depicted as loss of reflectance (Watt et al., 2008). Concerning the latter, the incorporation of $\mathrm{PM}_{10}$ concentration into the above-mentioned relationship allows for the generation of empirical dose-response functions for soiling (Brimblecombe and Grossi, 2005). The interaction of aerosols and air pollutants is complex (e.g. confined not only to the aerosol surface but is at least several hundred Angstroms deep) and must be taken into account from the boundary layer up to the stratosphere. In this connection, the uptake (e.g. via diffusion) of the gaseous pollutants on the solid aerosols can be influenced by the point defects existing in the crystals of the solid aerosols (Varotsos and Zellner, 2010; Lazaridou et al., 1985; Londos et al., 1996; Sarlis et al., 1997; Varotsos and Cracknell, 1994).

The DRFs are used for the assessment of tolerable pollution levels and to recommend target levels to be implemented in the future development of measurements on urban air quality in order to minimise the pollution effects on historic and cultural objects. In addition, they can be used on sites where there are no experimental results in order to make estimations of corrosion/soiling rates. According to previous studies implemented in Athens, carbon steel has been proven to be the material which suffers more from corrosion than other exposed metals/alloys. On the contrary, copper is the most durable (Tzanis et al., 2011). Another study has revealed that the greatest part of the deposited particle mass is not water soluble, while in the water soluble part there is an imbalance between the cations and anions with the cations surpassing the anions (Tzanis et al., 2009a).

In this study we present the most recent results from the UNECE/ICP Materials trend exposure programme 20112012 obtained at the Athens test site along with the corresponding measurements from previous exposure periods for comparison reasons. We also demonstrate a comparison between experimental results and theoretical corrosion/soiling estimations by employing the newly developed DRFs for the campaigns conducted in Athens, Greece.

\section{Experimentation}

For the purpose of MULTI-ASSESS and UNECE ICP Materials trend exposure programmes, a station has been installed in central Athens, Greece $\left(37^{\circ} 59^{\prime} 57^{\prime \prime} \mathrm{N}, 23^{\circ} 43^{\prime} 59^{\prime \prime} \mathrm{E}\right)$, since 2003. The main field exposure site is shown in Fig. 1 for the last exposure period, with exposure samples and the carousel on a rack as well as sheltered samples enclosed in a box under the rack. Specimens of the materials carbon steel $(\mathrm{C}<0.2 \%, \mathrm{P}<0.07 \%, \mathrm{Cr}<0.07 \%$ according to CSN 11373) (6 samples), weathering steel $(\mathrm{C}<0.12 \%$, Mn $0.3-$
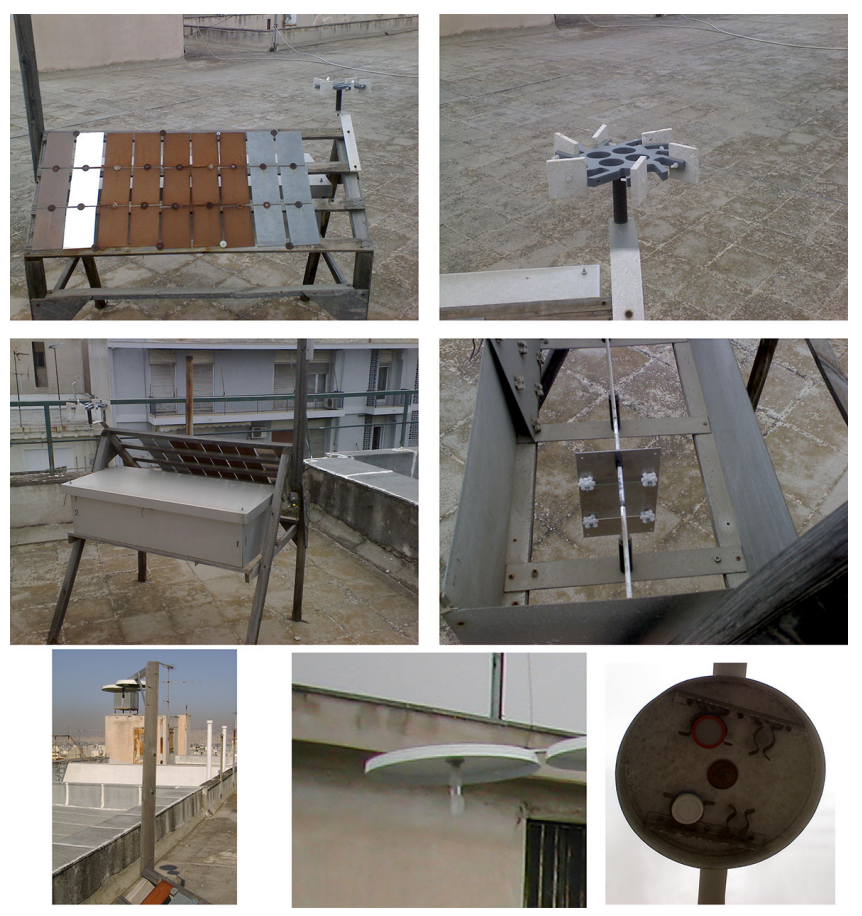

Figure 1. The exposure site in the centre of Athens (Greece). The top panel shows the carousel (on the right) and the main rack (on the left) with the material specimens. They consisted of an inclined plane and an aluminium box with open bottom (middle panel). The middle panel shows aluminium box (on the left) and the glass specimens inside the aluminium box (on the right). The bottom panel shows the diffusive passive samplers for the surface air pollutants measurements and the passive particle collector under the rain shield.

$0.8 \%$, Si $0.25-0.7 \%$, P $0.07-0.15 \%, \mathrm{~S}<0.04 \%$, Cr $0.5-$ $1.2 \%$, Ni $0.3-0.6 \%, \mathrm{Cu} 0.3-0.55 \%, \mathrm{Al}<0.01 \%$ ) (9 samples), zinc (99.99\%) (6 samples), copper (99\%, DIN 1787) (3 samples), aluminium (>99.5\%) (3 samples), limestone (6 samples) and modern glass (1 sample) were installed on the main rack. The vast majority of the specimens were in unsheltered conditions, while the modern glass was sheltered inside the open-bottomed aluminium box. The exposure time for modern glass and copper, as well as for three samples of carbon steel, weathering steel, zinc and limestone, was 1 year, while the rest of the samples are scheduled to be withdrawn at a later time. The withdrawn specimens were sent to the responsible subcentres in Europe (see Table 1) for further analysis and evaluation of soiling or corrosion.

In particular, for the determination of multi-pollutant effects on materials, a chemical analysis of the specimens was conducted and basic parameters such as the weight change, mass loss, surface recession, haze and the total deposited mass of particles per surface unit of glass $\left(\mathrm{TP} \mathrm{s}^{-1}\right)$ were calculated. For comparison reasons, as also indicated in the Introduction, the corrosion and soiling values for the exposure period 2011-2012 were complemented with the avail- 
Table 1. Responsible subcentres for the evaluation of corrosion or soiling of the exposed materials for the period 2011-2012.

\begin{tabular}{ll}
\hline Material & Responsible subcentre \\
\hline Carbon steel & SVUOM, Czech Republic \\
Weathering steel & CENIM/CSIC, Spain \\
Zinc & EMPA, Switzerland \\
Copper & KIMAB, Sweden \\
Limestone & BRE, Watford, UK \\
Modern glass & Univeristy Paris XII, LISA, France \\
\hline
\end{tabular}

able data collected previously (2003-2004, 2005-2006 and 2008-2009) in the frame of the MULTI-ASSESS and UNECE ICP Materials programmes, in which the Athens station has been involved.

In addition, the diffusive passive samplers for the surface air pollutant $\left(\mathrm{SO}_{2}, \mathrm{HNO}_{3}, \mathrm{HCOOH}, \mathrm{CH}_{3} \mathrm{COOH}, \mathrm{HCl}\right.$ and $\mathrm{HF}$ ) measurements and the passive particle collector (aerosols) that were used (shown also in Fig. 1), were prepared at the Swedish Environmental Research Institute (IVL). The samplers were mounted under a metal disc ca. $2 \mathrm{~m}$ above the ground in order to protect them from rain and direct sunshine and, after the exposure, they were returned to IVL for analysis. The main aim of these measurements was to correlate the pollutant concentrations with the degradation rate of the exposed material specimens.

\section{Results and discussion}

As mentioned before, in order to study the corrosion of structural metals/alloys (copper, zinc, carbon and weathering steel), the parameters "weight change" and "mass loss" were evaluated. Figures $2-4$ present the weight change and mass loss values obtained after the analysis of the exposed specimens. In these figures the experimental results of previous expositions are also presented. It should be mentioned that the presented values are the mean values obtained for the three specimens of each structural metal/alloy exposed during the aforementioned exposure periods.

The parameter weight change describes the difference in a specimen's mass after the exposure minus its initial mass. If the specimen was exposed under sheltered conditions, this parameter would be expected to be positive due to uptake processes (e.g. deposition) and the lack of any mass loss mechanism. In the case of unsheltered conditions, weight change can be positive or negative depending on the balance among uptake and loss mechanisms. According to the results obtained for the case of copper (Fig. 2a), mean weight change of samples exposed during 2011-2012 period is almost 1.5 times greater than that of the samples exposed during 2003 2004 (Tidblad et al., 2013).

The parameter mass loss expresses the difference in a specimen's initial mass minus the specimen's mass after re-
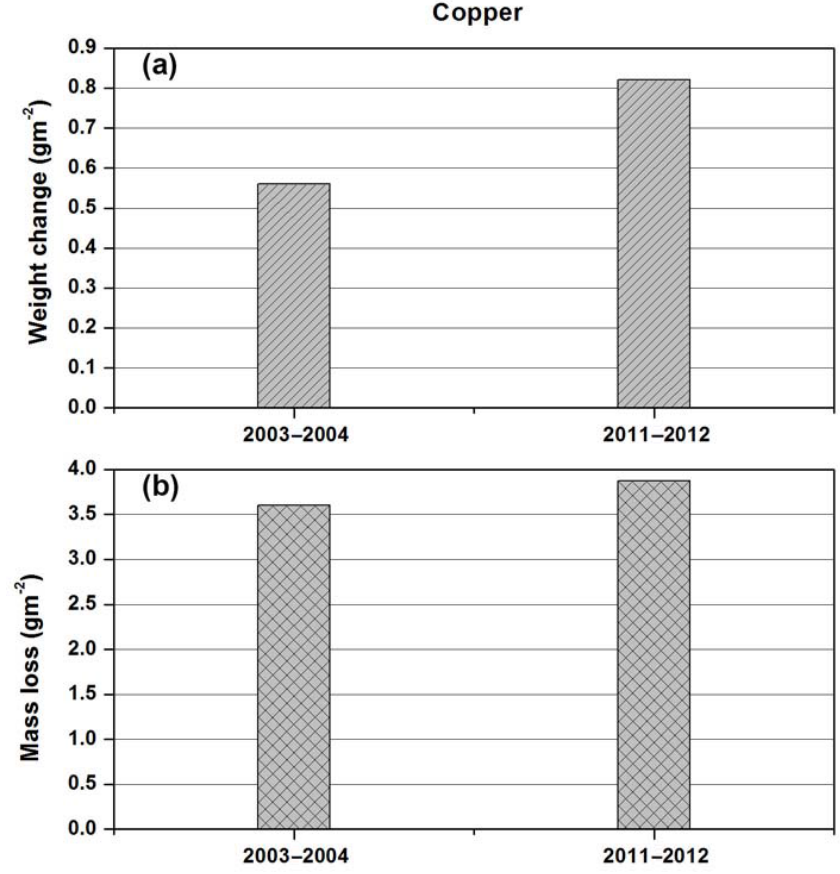

Figure 2. (a) Mean weight change and (b) mean mass loss of copper samples exposed during the periods 2003-2004 and 2011-2012.

moving its corroded part. It should be mentioned here that both the weight change and mass loss parameters are affected by the run-off and the chemical composition of the corrosion layer (Horalek et al., 2005). The experimental results of mass loss for copper, zinc and carbon steel are presented in Figs. 2b, $3 \mathrm{~b}$ and $4 \mathrm{~b}$. According to these results, mass loss of copper is shown to have increased since 2003-2004; however, this increase has been minimal (1.075 times greater). On the contrary, mass loss of zinc and carbon steel samples decreases continuously after the period 2005-2006. The greatest values of mass loss for both materials were recorded for the case of Athens, Greece, during that period. The last results denote a zinc mass loss of about $36 \%$ and a carbon steel mass loss of about $55 \%$ since that period. The corrosion rates of carbon steel are shown to have decreased significantly during 2011-2012, possibly due to the reduced levels of $\mathrm{SO}_{2}$ and $\mathrm{PM}_{10}$ which have been measured. In addition, the first results show that pollution has a significant effect on the corrosion rate of weathering steel. Mean mass loss of weathering steel samples during 2011-2012 exposition was evaluated to $82.8 \mathrm{~g} \mathrm{~m}^{-2}$ (Tidblad et al., 2013). Of all the exposed alloys, carbon and weathering steel appear to be the most sensitive to mass loss, while copper is the most durable. That means that steel is the most sensitive material to corrosion while copper suffered less from atmospheric corrosion. Considering future projections of climate change, an increase in temperature, relative humidity and precipitation (IPCC, 2013) - factors which favour corrosion rate - is expected. However, corrosion rate is also affected by pollutant 

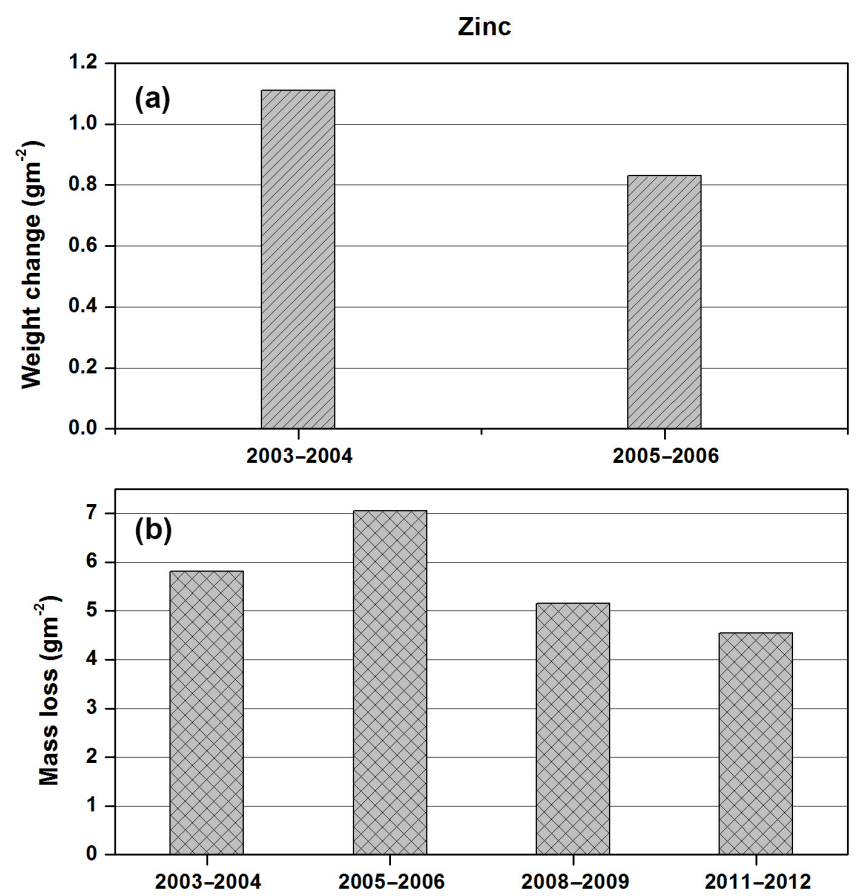

Figure 3. (a) Mean weight change of zinc samples exposed during the periods 2003-2004 and 2005-2006 and (b) mean mass loss of zinc samples exposed during the periods 2003-2004, 2005-2006, 2008-2009 and 2011-2012.

levels, which are generally decreasing (Cracknell and Varotsos, 2011; Varotsos and Cartalis, 1991). So the question of how much climate change affects the corrosion of materials needs a very careful approach.

In the case of zinc samples, chemical analyses were performed to water solutions of the corrosion products. These solutions were analysed for inorganic acids, formate $\left(\mathrm{CHOO}^{-}\right)$and acetate. The aim was the identification of the corrosive media which affected metal surfaces. The results cannot be used for a quantitative analysis but they are useful for qualitative conclusions about substances which mainly corrode zinc samples (Tidblad et al., 2013). The analysis showed that chloride ions, water-soluble sulfate and nitrates are involved in the corrosion processes of the exposed zinc samples in Athens. No traces of formate and acetate were found.

For the evaluation of the corrosion of limestone specimens exposed in unsheltered conditions, surface recession was calculated. This parameter is defined by the formula $R=\frac{W_{1}-W_{0}}{A \cdot \rho}$, where $W_{0}$ is the sample weight before the exposure, $W_{1}$ is the sample weight after the exposure, $A$ is the total surface area of the sample and $\rho$ is the density of the limestone. The results of surface recession for the limestone specimens in unsheltered conditions for 1 year are presented in Fig. 5 along with the same results obtained during previous exposure periods. Generally, the recession of limestone decreased slightly after the period 2005-2006, possibly due to
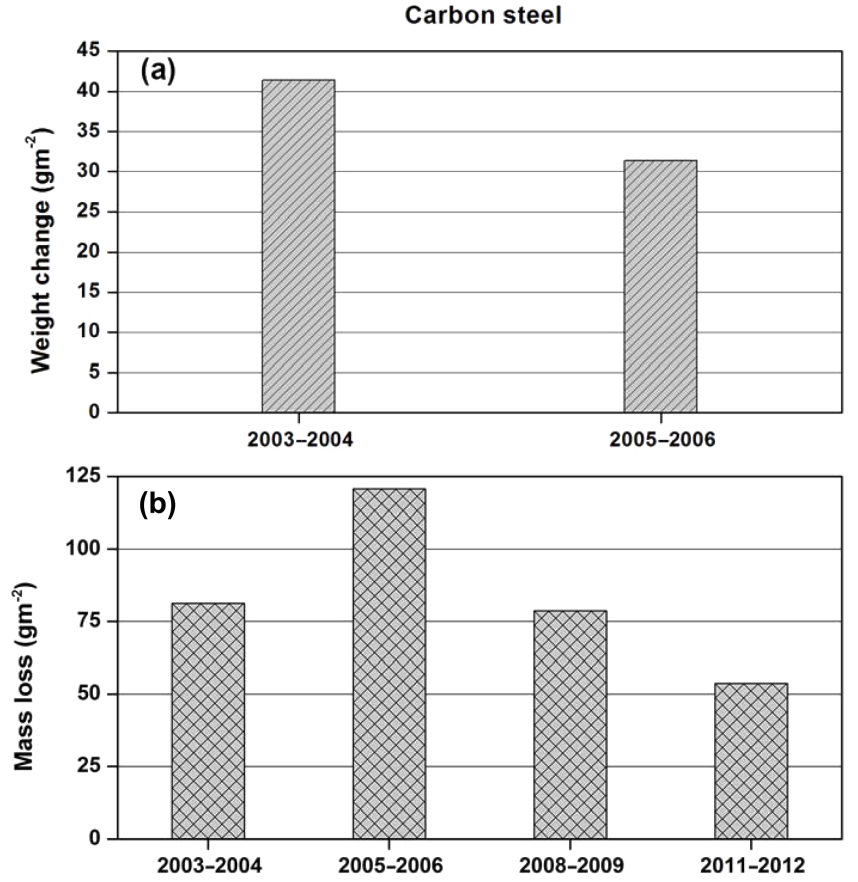

Figure 4. (a) Mean weight change of carbon steel samples exposed during the periods 2003-2004 and 2005-2006 and (b) mean mass loss of carbon steel samples exposed during the periods 2003-2004, 2005-2006, 2008-2009 and 2011-2012.

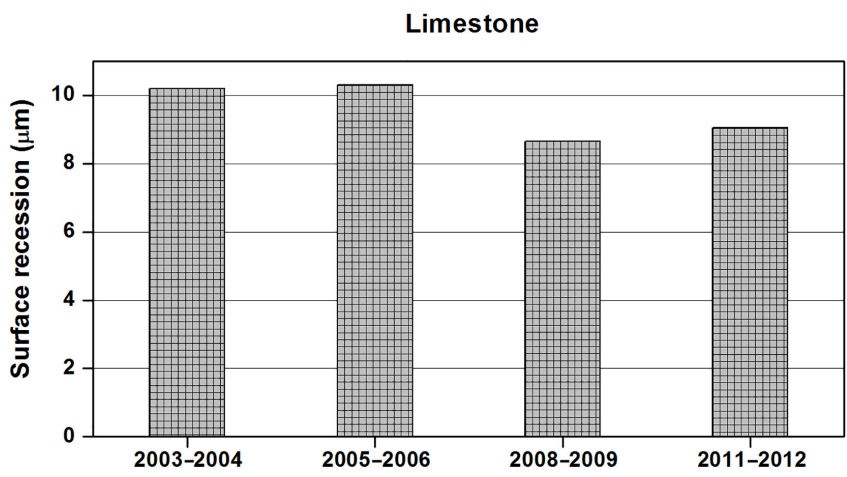

Figure 5. Surface recession of limestone exposed in unsheltered conditions for the periods 2003-2004, 2005-2006, 2008-2009 and 2011-2012.

the reduced pollution levels. It is also obvious from this figure that the recession during the last exposure period (20112012) is slightly higher than in the previous one, perhaps due to a small increase in $\mathrm{NO}_{2}$ concentration during this period.

Another material studied during this exposure period was modern glass. It is not a part of historic and cultural monuments but it is a material which is used widely in synchronous art as well as in other kinds of modern constructions. In addition to that, modern glass is also an ideal material for soiling studies because it is transparent, flat, non-porous and chemically inert. Due to these properties, modern glass does not 

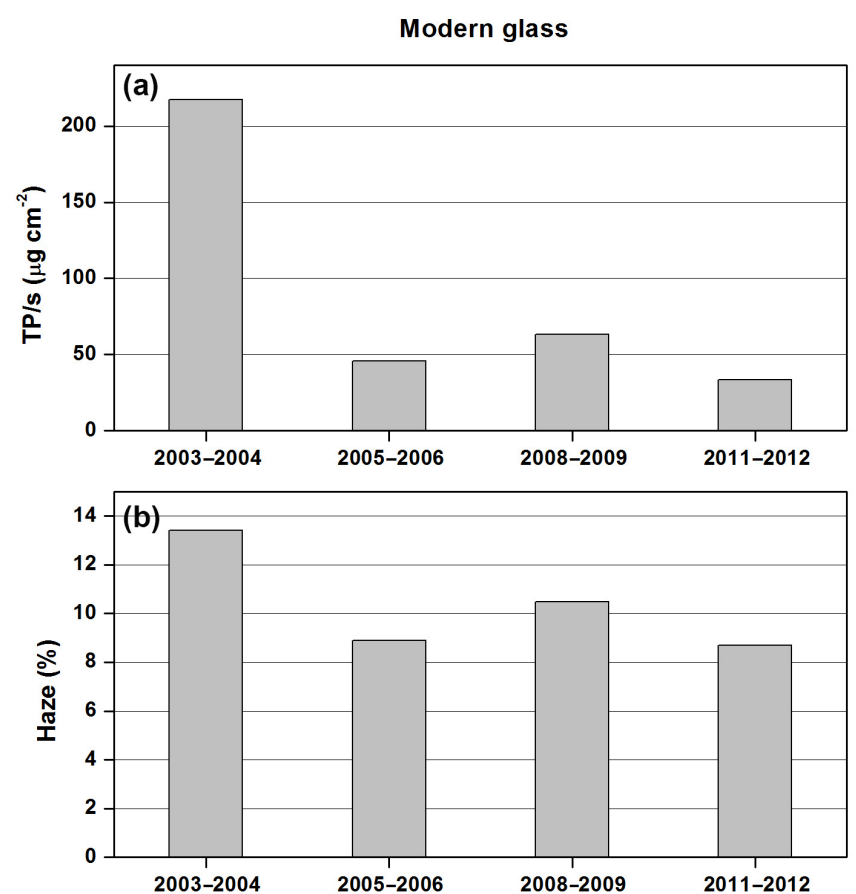

Figure 6. (a) $\mathrm{TP} \mathrm{s}^{-1}\left(\mu \mathrm{g} \mathrm{cm}^{-2}\right)$ and (b) haze ( \%) for modern glass exposed for the periods 2003-2004, 2005-2006, 2008-2009 and 2011-2012.

affect particles deposition and accumulation (Lombardo et al., 2010).

In order to evaluate soiling, two parameters are investigated: the total deposited mass of particles per surface unit of glass $\left(\mathrm{TP} \mathrm{s}^{-1}\right)$ in $\mu \mathrm{g} \mathrm{cm}^{-2}$ and haze defined as the ratio, expressed in percentage, of the diffused to directly transmitted light. Modern glass samples were placed under sheltered conditions during all exposure periods.

The obtained results for TP s${ }^{-1}$ and haze are presented in Fig. $6 \mathrm{a}$ and $\mathrm{b}$. TP $\mathrm{s}^{-1}$ shows a clear decreasing trend through the exposure periods. The maximum value was recorded during 2003-2004 and it is proven to be about 4 times greater than the next periods. The minimum value was recorded during the 2011-2012 exposure period. The range of haze is similar for the exposure periods 2005-2006, 2008-2009 and 2011-2012 while the minimum value is presented for 20112012 and the maximum for 2003-2004.

The corrosion or soiling values presented above and environmental parameters mentioned in Sect. 2, along with data from previous experimental campaigns, were analysed in order to develop the dose-response functions for corrosion and soiling for the studied materials. The results for DRFs (for the multi-pollutant situation except for the case of weathering steel) based on data from all the ICP Materials test sites are presented below in Eqs. (1)-(6) (Kucera et al., 2005, 2007; Watt et al., 2008; Verney-Carron and Lombardo, 2013) along with correlation coefficients $R^{2}$, root mean square deviations (RMSDs) and normalised root mean square devia-

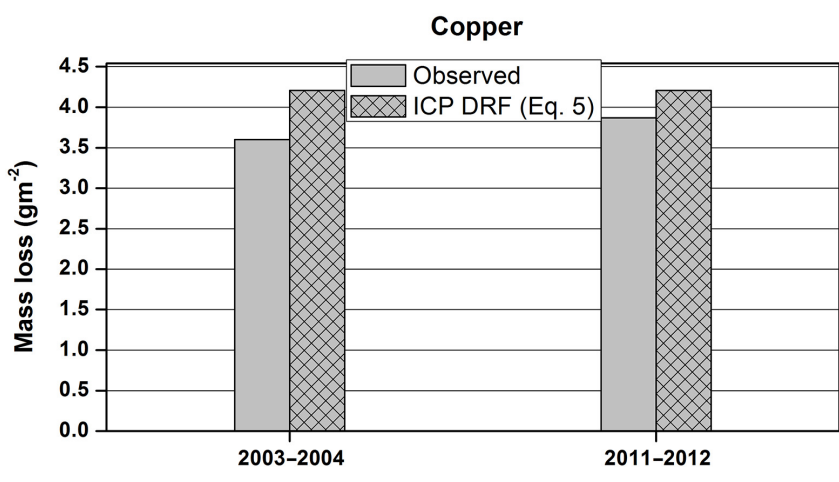

Figure 7. Experimental obtained mass loss values at Athens, Greece for the case of copper along with the predicted values by ICP DRF.

Table 2. Correlation coefficients $R^{2}$, root mean square deviations (RMSDs) and normalised root mean square deviations (NRMSDs) between observed and predicted values for Athens, Greece. The abbreviation "nss" declares a non-statistically-significant value at a $95 \%$ confidence interval while "ss" is a statistically significant value at a $95 \%$ confidence interval.

\begin{tabular}{llrr}
$\begin{array}{l}\text { Dose Response } \\
\text { Function }\end{array}$ & $R^{2}$ & $\begin{array}{r}\text { RMSD } \\
\text { NRMSD } \\
(\%)\end{array}$ \\
\hline Carbon steel (Eq. 1) & $0.972(\mathrm{ss})$ & 12.57 & 19 \\
Carbon steel for Athens (Eq. 7) & $0.999(\mathrm{ss})$ & 1.07 & 2 \\
Zinc (Eq. 2) & $0.581(\mathrm{nss})$ & 2.01 & 80 \\
Zinc for Athens (Eq. 8) & $0.995(\mathrm{ss})$ & 0.096 & 4 \\
Limestone (Eq. 3) & $0.556(\mathrm{nss})$ & 3.79 & 230 \\
Limestone for Athens (Eq. 9) & $0.653(\mathrm{ss})$ & 0.796 & 48 \\
Modern glass (Eq. 6) & $0.797(\mathrm{nss})$ & 2.14 & 48 \\
Modern glass for Athens (Eq. 10) & $0.809(\mathrm{ss})$ & 1.5 & 32 \\
\hline
\end{tabular}

tions (NRMSDs) between observed and predicted values for Athens, Greece. In addition to these, we present newly developed DRFs, Eqs. (7)-(10), along with the correlation coefficients $R^{2}$, RMSDs and NRMSDs between observed and new predicted values for carbon steel, zinc, limestone and modern glass for the case of Athens, Greece. The obtained values of these statistical parameters are given in Table 2 . For copper and weathering steel the available data were not adequate for developing new DRFs. All the DRFs presented below (Eqs. 1, 2, 3, 4, 5, 7, 8, 9) are valid for an exposure of 1 year except for modern glass (Eqs. 6, 10), where $t$ denotes the exposure duration in days. These DRFs are based on parameters already defined by the UNECE/ICP Materials group and were obtained by implementing non-linear regression analysis for carbon steel, zinc and limestone and multiple linear regression for the modern glass case. In the given equations the constants denote corrosion of materials due to factors which are not included in the presented equations. Two such factors are sunlight and wind. It should be noted that the time factor in the new DRF for modern glass in Eq. (10) remained the same as in Eq. (6) (see Lombardo et al., 2010). 
Carbon steel

$$
\begin{aligned}
& \mathrm{ML}=51+1.39\left[\mathrm{SO}_{2}\right]^{0.6} \mathrm{Rh}_{60} e^{f(T)} \\
& +1.29 \text { Rain }\left[\mathrm{H}^{+}\right]+0.593 \mathrm{PM}_{10} \\
& f(T)=\left\{\begin{array}{l}
0.15(T-10), T<10^{\circ} \mathrm{C} \\
-0.054(T-10), T \geq 10^{\circ} \mathrm{C}
\end{array}\right.
\end{aligned}
$$

Zinc

$$
\begin{gathered}
\mathrm{ML}=3.5+0.471\left[\mathrm{SO}_{2}\right]^{0.22} e^{0.018 \mathrm{Rh}+f(T)} \\
+0.041 \mathrm{Rain}\left[\mathrm{H}^{+}\right]+1.3\left[\mathrm{HNO}_{3}\right] \\
f(T)=\left\{\begin{array}{l}
0.062(T-10), T<10^{\circ} \mathrm{C} \\
-0.021(T-10), T \geq 10^{\circ} \mathrm{C}
\end{array}\right.
\end{gathered}
$$

Limestone

$$
\begin{aligned}
R & =4+0.0059\left[\mathrm{SO}_{2}\right] \mathrm{Rh}_{60}+0.054 \mathrm{Rain}\left[\mathrm{H}^{+}\right] \\
& +0.078\left[\mathrm{HNO}_{3}\right] \mathrm{Rh}_{60}+0.0258 \mathrm{PM}_{10}
\end{aligned}
$$

Weathering steel

$$
\begin{aligned}
& \mathrm{ML}=34\left[\mathrm{SO}_{2}\right]^{0.13} e^{0.020 \mathrm{Rh}+f(T)} \\
& f(T)=\left\{\begin{array}{l}
0.059(T-10), T \leq 10^{\circ} \mathrm{C} \\
-0.036(T-10), T>10^{\circ} \mathrm{C}
\end{array}\right.
\end{aligned}
$$

Copper

$$
\begin{aligned}
& \mathrm{ML}=4.21+0.00201\left[\mathrm{SO}_{2}\right]^{0.4}\left[\mathrm{O}_{3}\right] \mathrm{Rh}_{60} e^{f(T)} \\
& + \text { 0.0878Rain }\left[\mathrm{H}^{+}\right] \\
& f(T)=\left\{\begin{array}{l}
0.083(T-10), T \leq 10^{\circ} \mathrm{C} \\
-0.032(T-10), T>10^{\circ} \mathrm{C}
\end{array}\right.
\end{aligned}
$$

Modern glass

$$
H=\frac{0.2215\left[\mathrm{SO}_{2}\right]+0.1367\left[\mathrm{NO}_{2}\right]+0.1092 \mathrm{PM}_{10}}{1+\left(\frac{382}{t}\right)^{1.86}}
$$

Carbon steel for Athens

$$
\begin{gathered}
\mathrm{ML}=10+0.012\left[\mathrm{SO}_{2}\right]^{2.152} \mathrm{Rh}_{60} e^{f(T)} \\
+1.29 \text { Rain }\left[\mathrm{H}^{+}\right]+1.263 \mathrm{PM}_{10}
\end{gathered}
$$

Zinc for Athens

$$
\begin{gathered}
\mathrm{ML}=3.5+0.004\left[\mathrm{SO}_{2}\right]^{0.408} e^{0.082 \mathrm{Rh}+f(T)} \\
+0.041 \text { Rain }\left[\mathrm{H}^{+}\right]+0.138\left[\mathrm{HNO}_{3}\right] \\
f(T)=\left\{\begin{array}{l}
0.062(T-10), T<10^{\circ} \mathrm{C} \\
-0.021(T-10), T \geq 10^{\circ} \mathrm{C}
\end{array}\right.
\end{gathered}
$$

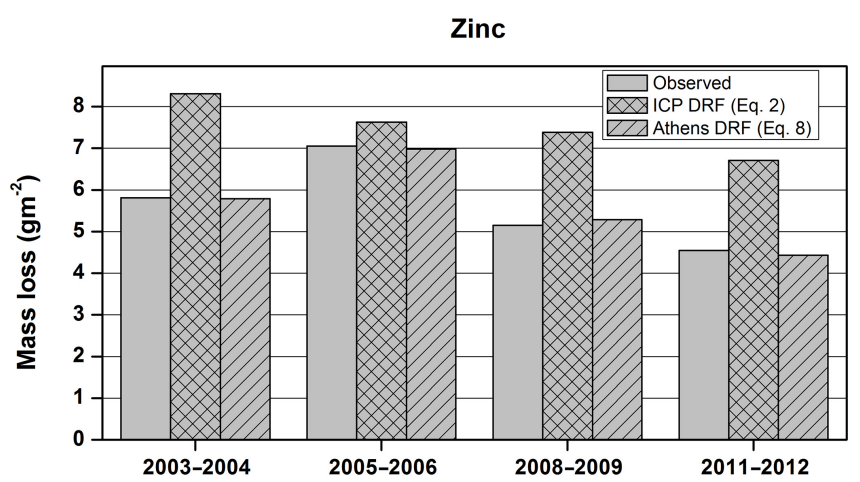

Figure 8. Experimental obtained mass loss values at Athens, Greece for the case of zinc along with the predicted values by DRFs.

Limestone for Athens

$$
\begin{aligned}
R=4 & +0.002\left[\mathrm{SO}_{2}\right] \mathrm{Rh}_{60}+0.054 \mathrm{Rain}\left[\mathrm{H}^{+}\right] \\
& +0.05\left[\mathrm{HNO}_{3}\right] \mathrm{Rh}_{60}+0.106 \mathrm{PM}_{10}
\end{aligned}
$$

Modern glass for Athens

$$
H=\frac{0.204\left[\mathrm{SO}_{2}\right]+0.016\left[\mathrm{NO}_{2}\right]+0.319 \mathrm{PM}_{10}}{1+\left(\frac{382}{t}\right)^{1.86}}
$$

where ML is the mass loss by corrosion, $\mathrm{g} \mathrm{m}^{-2} ; R$ is the surface recession, $\mu \mathrm{m}$ (absolute values); $H$ is haze $(\%) ; t$ is the exposure time in days; $\mathrm{Rh}$ is the annual average of relative humidity (\%), $\mathrm{Rh}_{60}=\mathrm{Rh}-60$ when $\mathrm{Rh}>60,0$ otherwise; $T$ is the annual average temperature $\left({ }^{\circ} \mathrm{C}\right)$; $\left[\mathrm{SO}_{2}\right]$ is the annual average concentration, $\mu \mathrm{g} \mathrm{m}^{-3} ;\left[\mathrm{O}_{3}\right]$ is the annual average concentration, $\mu \mathrm{g} \mathrm{m}^{-3} ;\left[\mathrm{NO}_{2}\right]$ is the annual average concentration, $\mu \mathrm{g} \mathrm{m}^{-3}$; Rain is the amount of precipitation, $\mathrm{mm} \mathrm{yr}^{-1} ;\left[\mathrm{HNO}_{3}\right]$ is the annual average concentration, $\mu \mathrm{g} \mathrm{m}^{-3} ; \mathrm{PM}_{10}$ is the annual average concentration, $\mu \mathrm{g} \mathrm{m}^{-3}$; $\left[\mathrm{H}^{+}\right]$is the annual average concentration $\left(\mathrm{mg} \mathrm{L}^{-1}\right)$. The unit for $\left[\mathrm{H}^{+}\right]$is not normally $\left(\mathrm{mol} \mathrm{L}^{-1}\right)$ used for this denomination, and the relation between $\mathrm{pH}$ and $\left[\mathrm{H}^{+}\right]$is therefore $\left[\mathrm{H}^{+}\right]=1007.9710^{-\mathrm{pH}} \approx 10^{3-\mathrm{pH}}$.

In Figs. 7-11 we present the above DRFs results for all the ICP Materials test sites (ICP DRF) and for Athens (Athens DRF) along with the (observed) experimental values obtained at Athens, Greece. For the case of weathering steel, the estimated mass loss is $100.6 \mathrm{~g} \mathrm{~m}^{-2}$ while, as mentioned before, the observed value is $82.8 \mathrm{~g} \mathrm{~m}^{-2}$. A general remark for the case of Athens is that the ICP DRF results for the case of metals/alloys overestimate the corrosion levels, while for limestone and modern glass they underestimate corrosion/soiling levels for all the exposure periods. Specifically, in the case of copper the overestimation is almost $17 \%$ for the 2003-2004 period and almost 9\% for the 2011-2012 period. In the case of zinc the overestimated mass loss ranges from 8 to $47 \%$ for all exposure periods. Carbon steel mass loss is greater than the observed by 3 to $35 \%$ through all 


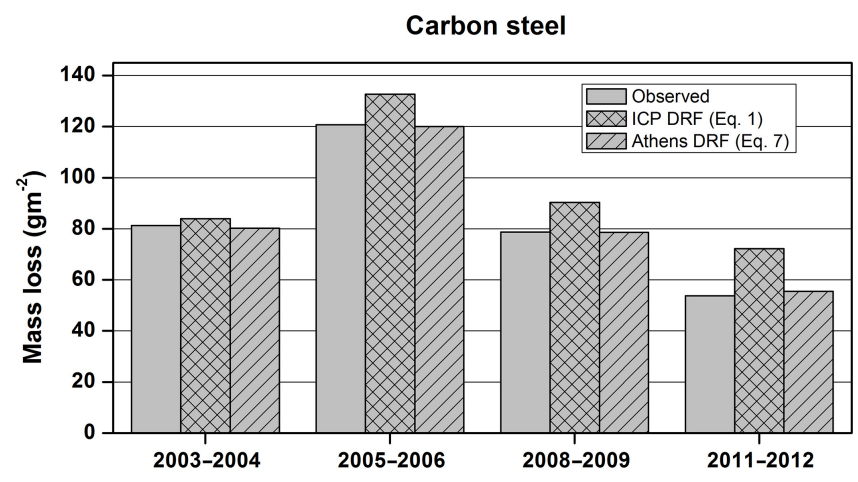

Figure 9. Experimental obtained mass loss values at Athens, Greece for the case of carbon steel along with the predicted values by DRFs.

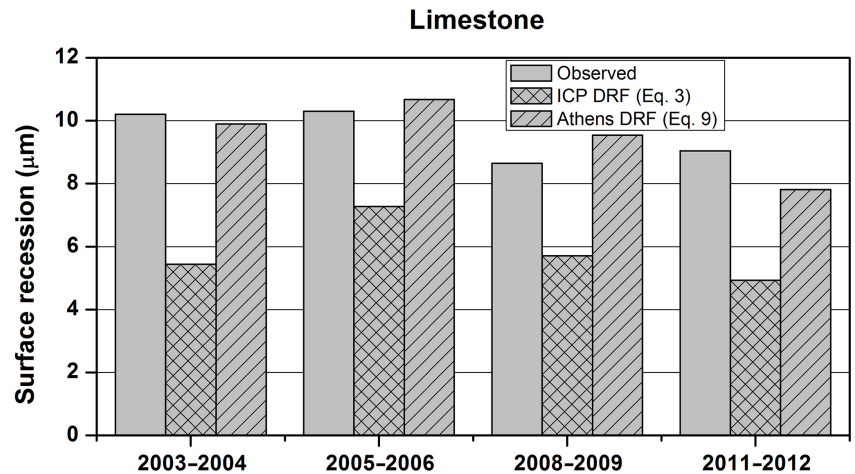

Figure 10. Experimental obtained surface recession values at Athens, Greece for the case of limestone along with the predicted values by DRFs.

exposure periods, while the weathering steel's mass loss is estimated to be almost $22 \%$ greater than the observed.

Limestone results reveal that DRF (Eq. 3) estimations underestimate corrosion levels by 29 to $47 \%$. In the case of modern glass the observed haze is 4 to $34 \%$ greater than the estimated values for all the exposure periods except for the case of 2005-2006 where an overestimation of about $6 \%$ is noticed.

DRFs for the Athens case present improved estimations. In particular, in the case of zinc, new DRF (Eq. 8) estimations underestimate mass loss by about 0 to $3 \%$ except for the case of the 2008-2009 exposure period where an overestimation of $3 \%$ is noticed. New estimations of carbon steel (Eq. 7) underestimate mass loss by about $1 \%$ for all exposure periods except for the last one where an overestimation of $3 \%$ is noticed. New DRF (Eq. 9) estimations for limestone recession are between $-14 \%$ (underestimation) and $10 \%$ (overestimation), while the estimated from Athens DRF (Eq. 10) modern glass haze differs from the observed values from -24 to $21 \%$. This range of differences may indicate that, for the Athens case, the parameters used in DRF for modern glass are not sufficient and more experimental data are needed in order to specify the factors which affect haze.

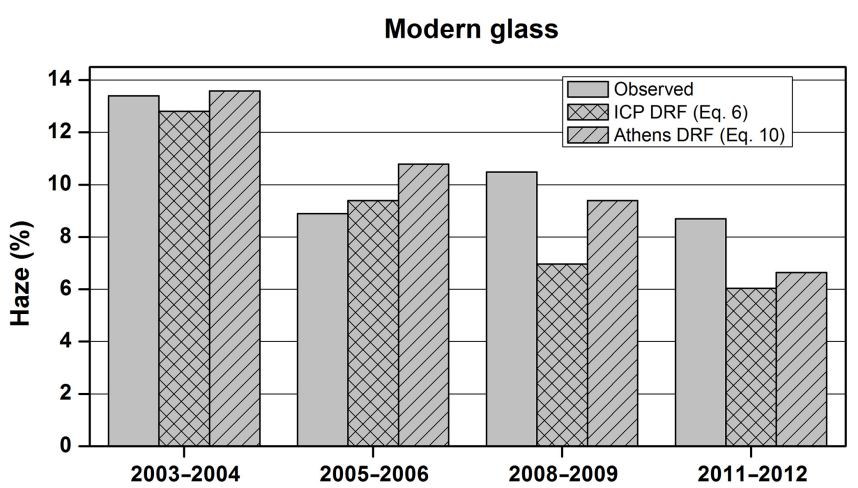

Figure 11. Experimental obtained haze values at Athens, Greece for the case of modern glass along with the predicted values by DRFs.

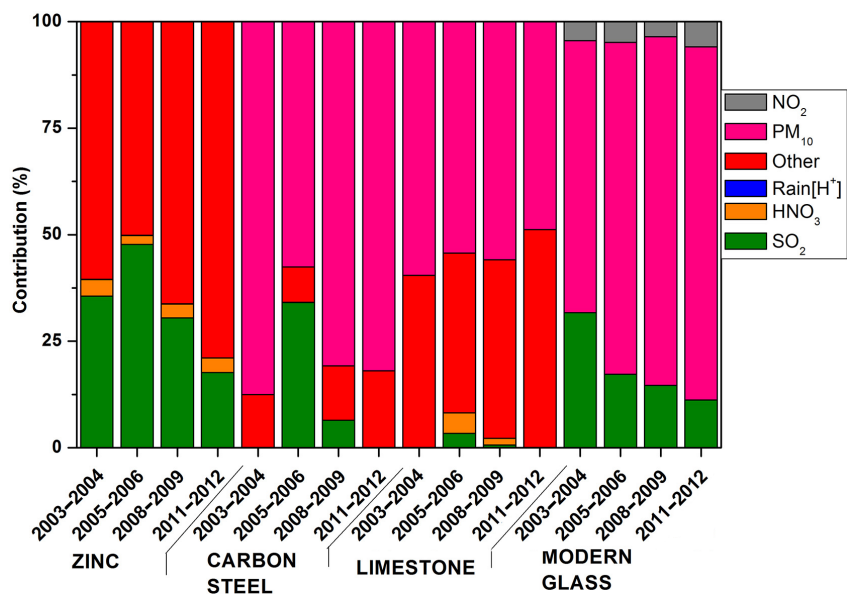

Figure 12. The percentage contribution of each Athens DRF factor to the total corrosion/soiling of each material for all exposure periods.

Fig. 12 presents the percentage contribution of each Athens DRF factor to the total corrosion/soiling of each material for all exposure periods.

\section{Conclusions}

According to the above-mentioned results, all the exposed materials except for copper present reduced corrosion/soiling levels through the years. Copper presents a greater mass loss of almost $7 \%$ during the last exposure period than during 2003-2004. According to DRFs, $\mathrm{O}_{3}$ is a parameter which affects copper mass loss, while it does not affect the other materials. So a possible explanation for this could be the increased level of $\mathrm{O}_{3}$ during $2011-2012\left(23.7 \mathrm{\mu g} \mathrm{m}^{-3}\right)$ compared to 2003-2004 (19.7 $\left.\mu \mathrm{g} \mathrm{m}^{-3}\right)$. Newly developed DRFs for the particular case of Athens, Greece improve the obtained estimations for corrosion and soiling of the materials under study. However, these DRFs will be re-evaluated when new data from the 2014-2015 exposure period are available. 


\section{Data availability}

Data concerning the period 2003-2004 are available in Annex A of MULTI-ASSESS publishable final report (Kucera et al., 2005) (zinc, carbon steel, copper), on doi:10.1016/j.scitotenv.2006.04.009 (Ionescu et al., 2006) (modern glass) and in Deliverable 4.0 of MULTI-ASSESS project (Massey and Yates, 2004) (limestone). Data concerning the period 2005-2006 are available in Report 53 of ICP Materials project (Kreislova et al., 2008) (carbon steel), in Report 54 of ICP Materials project (Reiss and Faller, 2007) (zinc), in Deliverable 17 of CULTSTRAT project (Tidblad et al., 2007) (limestone) and on doi:10.1016/j.scitotenv.2009.10.040 (Lombardo et al., 2010) (modern glass). Data concerning the period 2008-2009 are available in Report 62 of ICP Materials project (Tidblad et al., 2010) (zinc, carbon steel, limestone, modern glass). Data concerning the period 2011-2012 are available in Report 72 of ICP Materials project (Tidblad et al., 2013) (zinc, carbon steel, weathering steel, copper, limestone, modern glass).

Acknowledgements. We gratefully acknowledge the Ministry of Health and all the participants in the MULTI-ASSESS and ICP Materials programmes.

Edited by: M. Van Roozendael

Reviewed by: three anonymous referees

\section{References}

Brimblecombe, P. and Grossi, C. M.: Aesthetic thresholds and blackening of stone buildings, Sci. Total Environ., 349, 175-198, 2005.

Chattopadhyay, G., Chakraborthy, P., and Chattopadhyay, S.: MannKendall trend analysis of tropospheric ozone and its modeling using ARIMA, Theor. Appl. Climatol., 110, 321-328, doi:10.1007/s00704-012-0617-y, 2012.

Cracknell, A. P. and Varotsos, C. A.: Ozone depletion over Scotland as derived from Nimbus-7 TOMS measurements, Int. J. Remote Sens., 15, 2659-2668, 1994.

Cracknell, A. P. and Varotsos, C. A.: The present status of the total ozone depletion over Greece and Scotland: a comparison between Mediterranean and more northerly latitudes, Int. J. Remote Sens., 16, 1751-1763, 1995.

Cracknell, A. P. and Varotsos, C. A.: Fifty years after the first artificial satellite: from Sputnik 1 to ENVISAT, Int. J. Remote Sens., 28, 2071-2072, 2007.

Cracknell, A. P. and Varotsos, C. A.: New aspects of global climatedynamics research and remote sensing, Int. J. Remote Sens., 32, 579-600, doi:10.1080/01431161.2010.517807, 2011.

Doytchinov, S., Screpanti, A., Leggeri, G., and Varotsos, C.: UNECE international co-operative programme on effects on materials, including historic and cultural monuments, Report No. 68, Pilot study on inventory and condition of stock of materials at risk at United Nations Educational, Scientific and Cultural Organization (UNESCO) cultural heritage sites. Part I Methodology,
Italian national agency for new technologies, Energy and sustainable economic development (ENEA), Rome, Italy, 2011.

Ebel, A., Memmesheimer, M., and Jakobs, H. J.: Chemical perturbations in the planetary boundary layer and their relevance for chemistry transport modelling, Bound.-Lay. Meteorol., 125, 265-278, doi:10.1007/s10546-007-9157-x, 2007.

Efstathiou, M. N. and Varotsos, C. A.: On the altitude dependence of the temperature scaling behaviour at the global troposphere, Int. J. Remote Sens., 31, 343-349, 2010.

Efstathiou, M. N. and Varotsos, C. A.: Intrinsic properties of Sahel precipitation anomalies and rainfall, Theor. Appl. Climatol., 109, 627-633, 2012.

Efstathiou, M. N. and Varotsos, C. A.: On the 11 year solar cycle signature in global total ozone dynamics, Meteorol. Appl., 20, 72-79, 2013.

Ferm, M., De Santis, F., and Varotsos, C.: Nitric acid measurements in connection with corrosion studies, Atmos. Environ., 39, 66646672, doi:10.1016/j.atmosenv.2005.07.044, 2005.

Ferm, M., Watt, J., O'Hanlon, S., Santis, F., and Varotsos, C.: Deposition measurement of particulate matter in connection with corrosion studies, Anal. Bioanal. Chem., 384, 1320-1330, doi:10.1007/s00216-005-0293-1, 2006.

Horalek, S., Kuxenko, S., Singer, B., Wiedemann, G., and Woznik, E.: Model for multi-pollutant impact and assessment of threshold levels for cultural heritage. Evaluation of corrosion attack on copper and bronze of the broad field and targeted field exposure programme, EU 5FP RTD Project (project homepage: http://www.corr-institute.se/multi-assess/web/page.aspx, last access: 30 December 2016), 2005.

Ionescu, A., Lefèvre, R.-A., Chabas, A., Lombardo, T., Ausset, P., Candau, Y., and Rosseman, L.: Modeling of soiling based on silica-soda-lime glass exposure at six European sites, Sci. Total Environ., 369, 246-255, doi:10.1016/j.scitotenv.2006.04.009, 2006.

IPCC: Climate Change 2013: The Physical Science Basis, in: Contribution of Working Group I to the Fifth Assessment Report of the Intergovernmental Panel on Climate Change, edited by: Stocker, T. F., Qin, D., Plattner, G.-K., Tignor, M., Allen, S. K., Boschung, J., Nauels, A., Xia, Y., Bex, V., and Midgley, P. M., Cambridge University Press, Cambridge, United Kingdom and New York, NY, USA, 1535 pp., 2013.

Jacovides, C. P., Varotsos, C., Kaltsounides, N. A., Petrakis, M., and Lalas, D. P.: Atmospheric turbidity parameters in the highly polluted site of Athens basin, Renew. Energ., 4, 465-470, 1994.

Köhler, I., Dameris, M., Ackermann, I., and Hass, H.: Contribution of road traffic emissions to the atmospheric black carbon burden in the mid-1990s, J. Geophys. Res., 106, 17997-18014, doi:10.1029/2001JD900212, 2001.

Krapivin, V. F. and Shutko, A. M.: Information technologies for remote monitoring of the environment, Springer/Praxis, Chichester, UK, 2012.

Kreislova, K., Knotkova, D., Kvapil,J., and Divisova, H.: UN/ECE International Cooperative Programme on Effects on Materials, including Historic and Cultural Monuments, Report No 53: Results from the multi-pollutant programme - Corrosion attack on carbon steel after 1 year of exposure (2005-2006), SVUOM Ltd - Institute for Protection of Material, Prague, Czech Republic, 2008. 
Kucera, V., Tidblad, J., Samie, F., Schreiner, M., Melcher, M., Kreislova, K., Lefevre, R. A., Ionescu, A., Snethlage, R., Varotsos, C., De Santis, F., Mezinskis, G., Sidraba, I., Henriksen, J., Kobus, J., Ferm, M., Faller M., Yates, T., Watt, J., Hamilton, R., and O'Hanlon, S.: MULTI-ASSESS publishable final report, http://www.corr-institute.se/MULTI-ASSESS/ (last access: 30 December 2016), 2005.

Kucera, V., Tidblad, J., Kreislova, K., Knotkova, D., Faller, M., Reiss, D., Snethlage, R., Yates, T., Henriksen, J., Schreiner, M., Melcher, M., Ferm, M., Lefèvre, R.-A., and Kobus, J.: UN/ECE ICP Materials Dose-response Functions for the Multi-pollutant Situation, Water Air Soil Poll., 7, 249-258, doi:10.1007/s11267006-9080-z, 2007.

Lazaridou, M., Varotsos, C., Alexopoulos, K., and Varotsos, P.: Point defect parameters of LiF, J. Phys. C, 18, 3891-3895, doi:10.1088/0022-3719/18/20/015, 1985.

Lombardo, T., Ionescu, A., Chabas, A., Lefèvre, R.-A., Ausset, P., and Candau, Y.: Dose-response function for the soiling of silicasoda-lime glass due to dry deposition, Sci. Total Environ., 408, 976-984, doi:10.1016/j.scitotenv.2009.10.040, 2010.

Londos, C. A., Sarlis, N., Fytros, L. G., and Papastergiou, K.: Precursor defect to the vacancy-dioxygen center in Si, Phys. Rev. B, 53, 6900-6903, doi:10.1103/PhysRevB.53.6900, 1996.

Massey, S. W. and Yates, T.: Model for multipollutant impact and assessment of threshold levels for cultural heritage, Deliverable 4.0, Completion and evaluation of targeted field exposure, use of results for model validation and assessment of uncertainties, EU 5FP RTD Project, 2004.

Merlaud, A., Van Roozendael, M., van Gent, J., Fayt, C., Maes, J., Toledo-Fuentes, X., Ronveaux, O., and De Mazière, M.: DOAS measurements of $\mathrm{NO}_{2}$ from an ultralight aircraft during the Earth Challenge expedition, Atmos. Meas. Tech., 5, 2057-2068, doi:10.5194/amt-5-2057-2012, 2012.

Monks, P. S., Archibald, A. T., Colette, A., Cooper, O., Coyle, M., Derwent, R., Fowler, D., Granier, C., Law, K. S., Mills, G. E., Stevenson, D. S., Tarasova, O., Thouret, V., von Schneidemesser, E., Sommariva, R., Wild, O., and Williams, M. L.: Tropospheric ozone and its precursors from the urban to the global scale from air quality to short-lived climate forcer, Atmos. Chem. Phys., 15, 8889-8973, doi:10.5194/acp-15-8889-2015, 2015.

Ondov, J. M., Buckley, T. J., Hopke, P. K., Ogulei, D., Parlange, M. B., Rogge, W. F., Squibb, K. S., Johnston, M. V., and Wexler, A. S.: Baltimore Supersite: Highly time- and size-resolved concentrations of urban $\mathrm{PM}_{2.5}$ and its constituents for resolution of sources and immune responses, Atmos. Environ., 40, 224-237, doi:10.1016/j.atmosenv.2005.11.072, 2006.

Reiss, D. and Faller, M.: UN/ECE International Cooperative Programme on Effects on Materials, including Historic and Cultural Monuments, Report No 54: Results from the UN ECE zinc trend exposure: Corrosion attack on zinc after 1 year of exposure (November 2005-November 2006), EMPA-Swiss Federal Laboratories for Materials Testing and Research, Dübendorf, Switzerland, 2007.

Sarlis, N., Londos, C. A., and Fytros, L.: Origin of Infrared bands in neutron-irradiated Silicon, J. Appl. Phys., 81, 1645-1650, doi:10.1063/1.364020, 1997.

Tidblad, J., Kucera, V., Sjögren, L., Kreislova, K., Reiss, D., Yates, T., Lombardo, T., and Hamilton, R.: Assessment of Air Pollution Effects on Cultural Heritage - Management Strategies, De- liverable 17: Verified indicators and threshold levels for cultural heritage, Swerea KIMAB AB, Stockholm, Sweden, 2007.

Tidblad, J., Kreislova, K., Faller, M., Yates, T., Lombardo, T., and Grøntoft, T.: UN/ECE International Cooperative Programme on Effects on Materials, including Historic and Cultural Monuments, Report No 62: Results on corrosion and soiling from the 2008-2009 exposure programme for trend analysis, Swerea KIMAB AB, Stockholm, Sweden, 2010.

Tidblad, J., Kucera, V., Ferm, M., Kreislova, K., Brüggerhoff, S., Doytchinov, S., Screpanti, A., Grøntoft, T., Yates, T., De La Fuente, D., Roots, O., Lombardo, T., Simon, S., Faller, M., Kwiatkowski, L., Kobus, J., Varotsos, C., Tzanis, C., Krage, L., Schreiner, M., Melcher, M., Grancharov, I., and Karmanova, N.: Effects of air pollution on materials and cultural heritage: ICP Materials celebrates 25 years of research, Int. J. Corros., 2012, 496321, doi:10.1155/2012/496321, 2012.

Tidblad, J., Gordon, A., Kreislova, K., Faller, M., De la Fuente, D., Yates, T., and Verney-Carron, A.: UN/ECE International Cooperative Programme on Effects on Materials, including Historic and Cultural Monuments, Report No 72: Results of corrosion and soiling from the 2011-2012 exposure programme for trend analysis, Swerea KIMAB AB, Stockholm, Sweden, 2013.

Tzanis, C., Varotsos, C., Ferm, M., Christodoulakis, J., Assimakopoulos, M. N., and Efthymiou, C.: Nitric acid and particulate matter measurements at Athens, Greece, in connection with corrosion studies, Atmos. Chem. Phys., 9, 8309-8316, doi:10.5194/acp-9-8309-2009, 2009a.

Tzanis, C., Tsivola, E., Efstathiou, M., and Varotsos, C.: Forest fires pollution impact on the solar UV irradiance at the ground, Fresen. Environ. Bull., 18, 2151-2158, 2009b.

Tzanis, C., Varotsos, C., Christodoulakis, J., Tidblad, J., Ferm, M., Ionescu, A., Lefevre, R.-A., Theodorakopoulou, K., and Kreislova, K.: On the corrosion and soiling effects on materials by air pollution in Athens, Greece, Atmos. Chem. Phys., 11, 12039-12048, doi:10.5194/acp-11-12039-2011, 2011.

Varotsos, C. and Cartalis, C.: Re-evaluation of surface ozone over Athens, Greece, for the period 1901-1940, Atmos. Res., 26, doi:10.1016/0169-8095(91)90024-Q, 1991.

Varotsos, C. A. and Cracknell, A. P.: Remote sounding of minor constituents in the stratosphere and heterogeneous reactions of gases at solid interfaces, Int. J. Remote Sens., 15, 1525-1530, doi:10.1080/01431169408954182, 1994.

Varotsos, C. A. and Zellner, R.: A new modeling tool for the diffusion of gases in ice or amorphous binary mixture in the polar stratosphere and the upper troposphere, Atmos. Chem. Phys., 10, 3099-3105, doi:10.5194/acp-10-3099-2010, 2010.

Varotsos, C., Kalabokas, P., and Chronopoulos, G.: Association of the laminated vertical ozone structure with the lowerstratospheric circulation, J. Appl. Meteorol., 33, 473-476, doi:10.1175/1520-0450(1994)033<0473:AOTLVO>2.0.CO;2, 1994.

Varotsos, C., Tzanis, C., and Cracknell, A.: The enhanced deterioration of the cultural heritage monuments due to air pollution, Environ. Sci. Pollut. R., 16, 590-592, doi:10.1007/s11356-0090114-8, 2009.

Varotsos, C., Efstathiou, M., Tzanis, C., and Deligiorgi, D.: On the limits of the air pollution predictability: the case of the surface ozone at Athens, Greece, Environ. Sci. Pollut. R., 19, 295-300, doi:10.1007/s11356-011-0555-8, 2012. 
Varotsos, C., Christodoulakis, J., Tzanis, C., and Cracknell, A. P.: Signature of tropospheric ozone and nitrogen dioxide from space: A case study for Athens, Greece, Atmos. Environ., 89, 721-730, doi:10.1016/j.atmosenv.2014.02.059, 2014.

Verney-Carron, A. and Lombardo, T.: UN/ECE International Cooperative Programme on Effects on Materials, including Historic and Cultural Monuments, Report No 74: Results of the exposure of modern glass 2008-2012 and soiling dose-response functions, Laboratoire Interuniversitaire des Systèmes Atmosphérique (LISA), Paris, France, 2013.
Watt, J., Jarrett, D., and Hamilton, R.: Dose-response functions for the soiling of heritage materials due to air pollution exposure, Sci. Total Environ., 400, 415-424, doi:10.1016/j.scitotenv.2008.07.024, 2008.

Xue, Y., He, X. W., Xu, H., Guang, J., Guo, J. P., and Mei, L. L.: China Collection 2.0: The aerosol optical depth dataset from the synergetic retrieval of aerosol properties algorithm, Atmos. Environ., 95, 45-58, doi:10.1016/j.atmosenv.2014.06.019, 2014. 